\title{
Marek's Disease in A Flock Of 32 - Week Old Commercial Laying Birds
}

\author{
Barde IJ, Obishakin ET, Muraina IA, Wungak YS, Lapang HB, Tekki IS, Makanju OA, Waziri \\ AI, Durbi IAA, Olushola G, Aliyu S, Karaye K, Ezeanyika OU, Woma TY and Muhammad M \\ M. \\ National Veterinary Research Institute Vom Plateau State Nigeria
}

*Corresponding Author: Barde IJ, National Veterinary Research Institute Vom Plateau State Nigeria, Email: israelbarde@yahoo.com.

\begin{abstract}
Marek's disease (MD) is a highly contagious viral neoplastic disease in chickens. The disease is characterized by the presence of $T$ cell lymphoma as well as infiltration of nerves and organs by lymphocytes. Organs that are commonly affected include the ovary, spleen, liver, kidneys, lungs, heart, proventriculus and adrenals.This is a Marek's disease acase report in 32weeks layer with the following post-mortem findings:moderately emaciation, areas of whitish nodules on the kidney, liver and spleen, varying from 2-8mm in diameter, liver and spleen severely enlarged, moderate enlargement of sciatic nerve and kidneys. Histopathologically there were necrosis and desquamation of the hepatocytes with severe lymphocytic infiltration and lymphocytic infiltration of the spleen.
\end{abstract}

Keywords: Marek's disease, adult bird, case report.

\section{INTRODUCTION:}

Marek's disease (MD) is a highly contagious viral neoplastic disease in chickens. It is named after József Marek, a Hungarian veterinarian. Marek's disease is caused by an alpha herpesvirus known as 'Marek's disease virus' (MDV) or Gallid alpha herpesvirus 2 (GaHV-2) (Davison and Andrew, 2016). The disease is characterized by the presence of $\mathrm{T}$ cell lymphoma as well as infiltration of nerves and organs by lymphocytes (Hirai, 2001). Viruses related to MDV appear to be benign and can be used as vaccine strains to prevent Marek's disease. For example, the related Herpesvirus of Turkeys (HVT), causes no apparent disease in turkeys and continues to be used as a vaccine strain for prevention of Marek's disease. Birds infected with GaHV-2 can be carriers and shedders of the virus for life. Newborn chicks are protected by maternal antibodies for a few weeks. After infection, microscopic lesions are present after one to two weeks, and gross lesions are present after three to four weeks. The virus is spread in dander from feather follicles and transmitted by inhalation (Fenner et al., 1993). In Nigeria, MD was first reported in1962, since then there have been

ARC Journal of Animal and Veterinary Sciences reports in Ibadan, Jos and other parts of the country (Hill and Davis, 1962; Nawathe et al., 1978; Adene and Akpavie, 1997; Olabode et al., 2009; Okwor and Eze, 2011; Wakawa et al., 2012; Jwander et al., 2012, Jwander et al., 2014).

\subsection{Aetiologic Agent}

MD is caused by herpesvirus. There are three serotypes; serotype 1,2 and 3. But virulence and oncogenicity are associated only with serotype 1 Marek's disease virus (MDV) (OIE, 2010). The virions are commonly seen in the nucleus and rarely in the cytoplasm or extracellular spaces. There are two morphological forms: Hexagonal nucleocapsids (85-100 $\mathrm{nm}$ in diameter) and Enveloped virus particles in keratinizing cells measuring 273-400 nm (OIE, 2010).

\subsection{Species and Age Affected}

MD is primarily a disease of domestic chicken. It affect chickens as early as 5 weeks of age and commonly between 10-15 weeks of age occasionally 35 weeks; turkeys, quails and other species are less susceptible (Hirai, 2001).

\subsection{Mode of Transmission}

Transmission by direct and indirect contact between birds and the route of infection is 
airborne. The infected birds remain viremic for life (Davison and Andrew, 2016).

\subsection{Clinical Signs}

Six syndromes are known to occur after infection with Marek's disease. These syndromes may overlap. Classical Marek's disease or neurolymphomatosis causes asymmetric paralysis of one or more limbs. With vagus nerve involvement, difficulty in breathing or dilation of the crop may occur. Besides lesions in the peripheral nerves, there are frequently lymphomatous infiltration/tumours in the skin, skeletal muscle and visceral organs. Organs that are commonly affected include the ovary, spleen, liver, kidneys, lungs, heart, proventriculus and adrenals.

Acute Marek's disease is an epidemic in a previously uninfected or unvaccinated flock, causing depression, paralysis, and death in a large number of birds (up to $80 \%$ ). Ocular lymphomatosis causes lymphocyte infiltration of the iris (making the iris turn grey), unequal size of the pupils, and blindness. Cutaneous Marek's disease causes round, firm lesions at the feather follicles (Fenner et al., 1993). Atherosclerosis is induced in experimentally infected chickens (Fabricant and Fabricant, 1999). There is immunosuppression - impairment of the Tlymphocytes which prevents competent immunological response against pathogenic challenge and the affected birds become more susceptible to disease conditions such as coccidiosis and Escherichia coli infection (Islam et al., 2002). Furthermore, without stimulation by cell-mediated immunity, the humoral immunity conferred by the B-cell lines from the Bursa of Fabricius also shuts down, thus resulting in birds that are totally immunocompromised (Islam et al., 2002). Many birds die suddenly without symptoms ((Fenner et al., 1993).

\subsection{Pathogenesis}

Entry \& replication

Acute cytolytic phase

Latent infection

Another phase of cytolytic infection

Proliferative phase ((Davison and Andrew, 2016).

\subsection{Diagnosis}

Diagnosis of lymphoid tumors in poultry is complicated due to multiple etiological agents capable of causing very similar tumors. It is not uncommon that more than one avian tumor virus can be present in a chicken, thus one must consider both the diagnosis of the disease/tumors (pathological diagnosis) and of the virus (etiological diagnosis). A step-wise process has been proposed for diagnosis of Marek's disease which includes (1) history, epidemiology, clinical observations and gross necropsy, (2) characteristics of the tumor cell, and (3) virological characteristics (Witter et al., 2010). The demonstration of peripheral nerve enlargement along with suggestive clinical signs in a bird that is around three to four months old (with or without visceral tumors) is highly suggestive of Marek's disease. Histological examination of nerves reveals infiltration of pleomorphic neoplastic and inflammatory lymphocytes. Peripheral neuropathy should also be considered as a principal rule-out in young chickens with paralysis and nerve enlargement without visceral tumors, especially in nerves with interneuronal edema and infiltration of plasma cells (Bacon et al., 2001).

The presence of nodules on the internal organs may also suggest Marek's disease, but further testing is required for confirmation. This is done through histological demonstration of lymphomatous infiltration into the affected tissue. A range of leukocytes can be involved, including lymphocytic cell lines such as large lymphocyte, lymphoblast, primitive reticular cells, and occasional plasma cells, as well as macrophage and plasma cells. The $\mathrm{T}$ cells are involved in the malignancy, showing neoplastic changes with evidence of mitosis. The lymphomatous infiltrates need to be differentiated from other conditions that affect poultry including lymphoid leukosis and reticuloendotheliosis, as well as an inflammatory event associated with hyperplastic changes of the affected tissue ((Bacon et al., 2001). Key clinical signs as well as gross and microscopic features that are most useful for differentiating Marek's disease from lymphoid leukosis and reticuloendotheliosis include (1) Age: MD can affect birds at any age, including $<16$ weeks of age; (2) Clinical signs: Frequent wing and leg paralysis; (3) Incidence: $>5 \%$ in unvaccinated flocks; (4) Potential nerve enlargement; (5) Interfollicular tumors in the bursa of Fabricius; (6) CNS involvement; (7) Lymphoid proliferation in skin and feather follicles; (8) Pleomorphic lymphoid cells in nerves and tumors; and (9) T-cell lymphomas (OIE, 2010). In addition to gross pathology and histology, other advanced procedures used for a definitive 
diagnosis of Marek's disease include immunohistochemistry to identify cell type and virus-specific antigens, standard and quantitative PCR for identification of the virus, virus isolation to confirm infections, and serology to confirm/exclude infections. The World Organisation for Animal Health (OIE) reference laboratory for Marek's disease is Avian Viral Oncogenesis group (led by Professor Venugopal Nair OBE) at The Pirbright Institute, UK. PCR blood testing can also detect Marek's Disease, and proper testing can differentiate between a vaccinated bird with antibodies and a true positive for Marek's Disease (WHO, 2018).

\subsection{Treatment}

Mareks Disease is not treatable, however supportive care can help. It is recommended that all flocks positive for Marek's Disease remain closed, with no bird being introduced or leaving the flock. Strict bio security and proper cleaning is essential, using products like Activated Oxine or Virkon $\mathrm{S}$ and reducing dander buildup in the environment. Proper diet, regular deworming and vitamin supplements can also help keep infected flocks healthier. Reducing stress is also a key component, as stress will often bring about illness in birds infected with Mareks Disease (OIE, 2010; WHO, 2018).

\subsection{Prevention and Control}

Vaccination is the only known method to prevent the development of tumors when chickens are infected with the virus. However, administration of vaccines does not prevent transmission of the virus, i.e., the vaccine is not sterilizing (Hirai, 2001). However, it does reduce the amount of virus shed in the dander, hence reduces horizontal spread of the disease. Marek's disease does not spread vertically. Before the development of the vaccine for Marek's disease, Marek's disease caused substantial revenue loss in the poultry industries of the United States and the United Kingdom. The vaccine can be administered to one-day-old chicks through subcutaneous inoculation or by in ovo vaccination when the eggs are transferred from the incubator to the hatcher. In ovo vaccination is the preferred method, as it does not require handling of the chicks and can be done rapidly by automated methods. Immunity develops within two weeks (Fenner, 1993).

However, because vaccination does not prevent infection with the virus, Mareks is still transmissible from vaccinated flocks to other birds, including the wild bird population. The first Marek's disease vaccine was introduced in 1970. The disease would cause mild paralysis, with the only identifiable lesions being in neural tissue. Mortality of chickens infected with Marek's disease was quite low. Decades after the first vaccine was introduced, current strains of Marek Virus cause lymphoma formation on throughout the chicken's body and mortality rates have reached $100 \%$ in unvaccinated chickens. The Marek's disease vaccine is a leaky vaccine, which means that only the symptoms of the disease are prevented (OIE, 2010). Infection of the host and the transmission of the virus are not inhibited by the vaccine. This contrasts with most other vaccines, where infection of the host is prevented. Under normal conditions, highly virulent strains of the virus are not selected. A highly virulent strain would kill the host before the virus would have an opportunity to transmit to other potential hosts and replicate. Thus, less virulent strains are selected. These strains are virulent enough to induce symptoms but not enough to kill the host, allowing further transmission. However, the leaky vaccine changes this evolutionary pressure and permits the evolution of highly virulent strains (Read et al., 2015). The vaccine's inability to prevent infection and transmission allows the spread of highly virulent strains among vaccinated chickens. The fitness of the more virulent strains are increased by the vaccine. The evolution of Marek's disease due to vaccination has had a profound effect on the poultry industry. All chickens across the globe are now vaccinated against Marek's disease (birds hatched in private flocks for laying or exhibition are rarely vaccinated). Highly virulent strains have been selected to the point that any chicken that is unvaccinated will die if infected. Other leaky vaccines are commonly used in agriculture. One vaccine in particular is the vaccine for avian influenza. Leaky vaccine use for avian influenza can select for virulent strains which could potentially be transmitted to humans ((Read et al., 2015).

\subsection{Case History}

On 3rd December, 2018, one carcass of black Harco, age 32 weeks was presented to the Central Diagnostic Laboratory, NVRI Vom. Initial flock size of 1600 but now 1395. Mortality: 205 (13\%) at the time of presentation. Source of birds: 
Commercial hatchery. Source of feeds: Chukun feeds. Source of water: Well water. Management system: Deep litter. Clinical signs observed include: neck twisting (torticollis).

\subsection{Vaccination History}

The birds were given the following: Infectious bursa disease vaccine (IBDV), Newcastle disease vaccine Lasota (NDVL), Fowl pox vaccine (FPV), Fowl typhoid vaccine (FTV), Fowl cholera vaccine (FCV) and Newcastle disease vaccine Komarov (NDVK). Source of vaccines: National veterinary research institute (NVRI), Vom.

\subsection{Postmortem Findings}

The carcass was moderately emaciated. Areas of whitish nodules on the kidney, liver and spleen, varying from $2-8 \mathrm{~mm}$ in diameter. Liver and spleen: severe enlargement. Moderate enlargement of sciatic nerve. Moderate enlargement of kidneys.

Plate I. Emaciation/hepatomegaly with nodular lesions

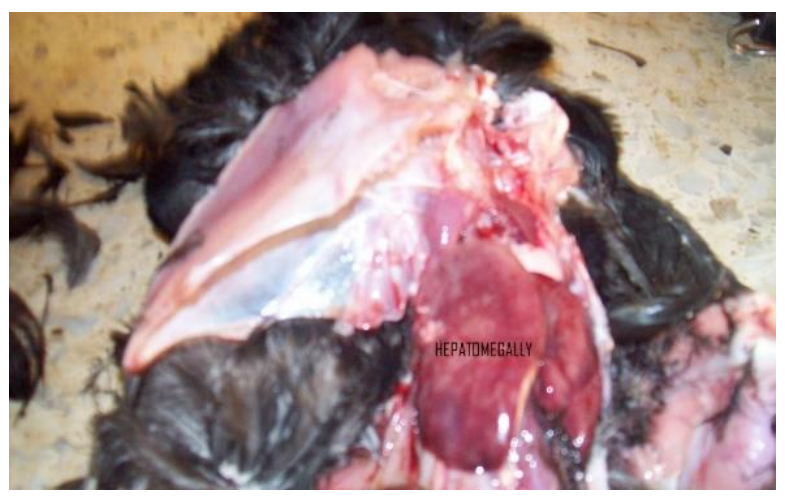

Plate II. Spleenomegaly with nodular lesions

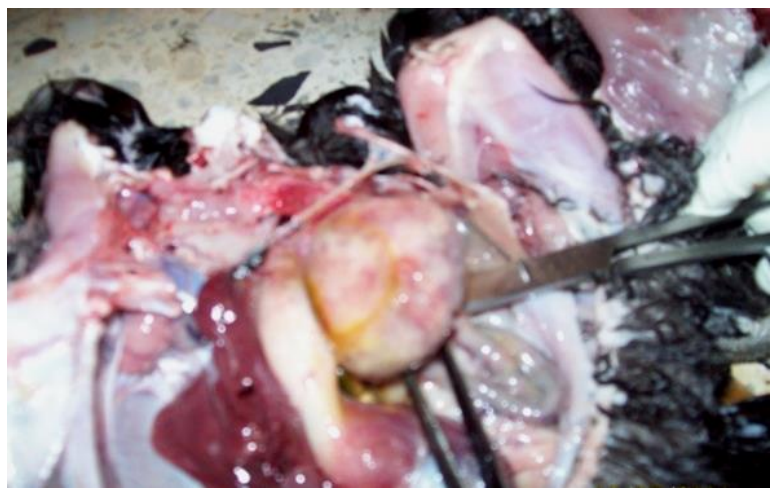

Plate III. Enlarged kidneys with nodular lesions

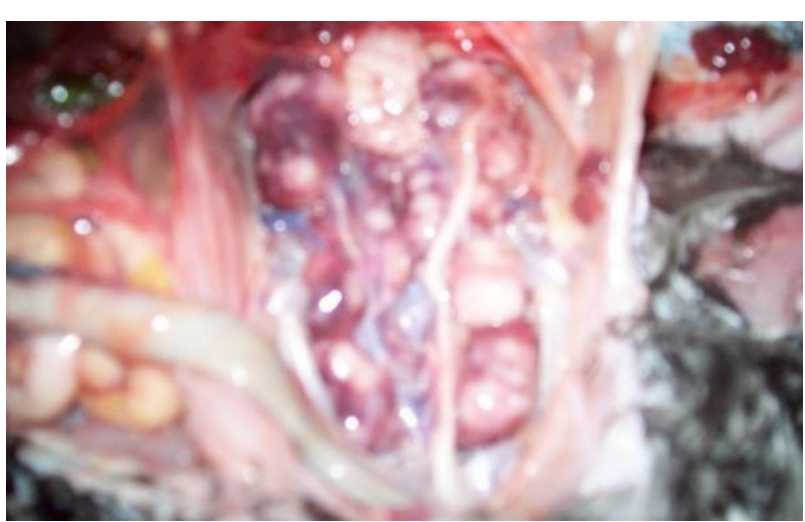

Plate IV: Enlarged sciatic nerve

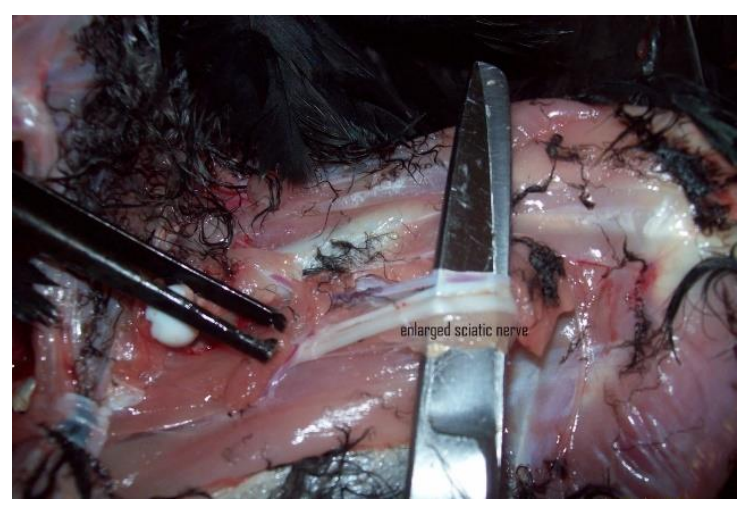

\subsection{Differential Diagnosis}

Marek's disease

Lymphoid leucosis

Newcastle disease

Vitamins /minerals deficiency

\subsection{Tentative Diagnosis}

Marek's Disease.

\subsection{Diagnostic Plan}

Tissue samples were sent to virology, bacteriology, parasitology and histopathology laboratories for analysis.

\subsection{Laboratory Findings}

Bacteriology: No organism isolated.

Parasitology: No parasite found

Virology: Negative for AI \& ND

Histopathology: Lesions as on slides.

Plate V: Necrosis and desquamation of the hepatocytes with severe lymphocytic infiltration 


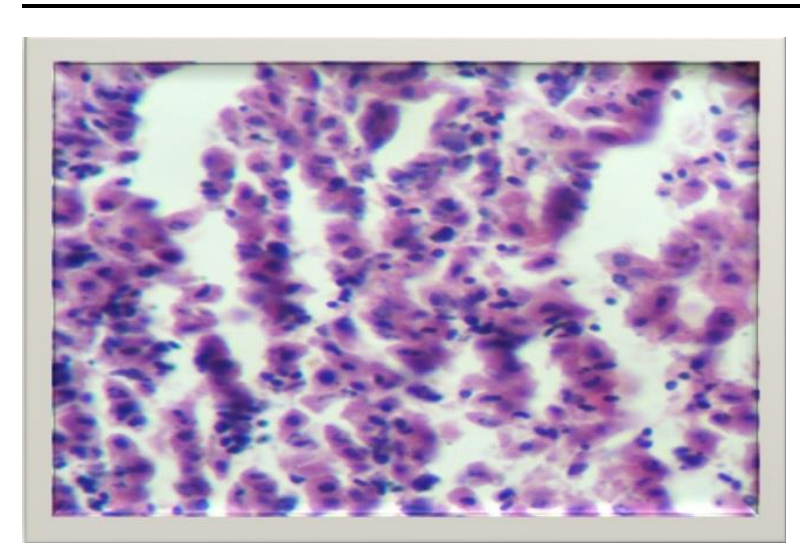

Nigeria: Current options and future developments in its control.NigeriaVeterinaryJournal, 18:2-18.

[2] Bacon LD, Witter RL, Silva RF (October 2001). "Characterization and experimental reproduction of peripheral neuropathy in White Leghorn chickens". Avian Pathology. 30 (5): 487-99. doi:10.1080/03079450120078680. PMID 19184938.

[3] Davison, Andrew (27 January 2016). "Rename species in the family Herpesviridae to incorporate a subfamily designation" (PDF). International Committee on Taxonomy of Viruses (ICTV). p. 2. Retrieved 7 May 2019.

[4] Fabricant CG, Fabricant J (November 1999). "Atherosclerosis induced by infection with Marek's disease herpesvirus in chickens". American Heart Journal. 138 (5 Pt 2): S465-8. doi:10.1016/S0002-8703(99)70276-0. PMID 10539849.

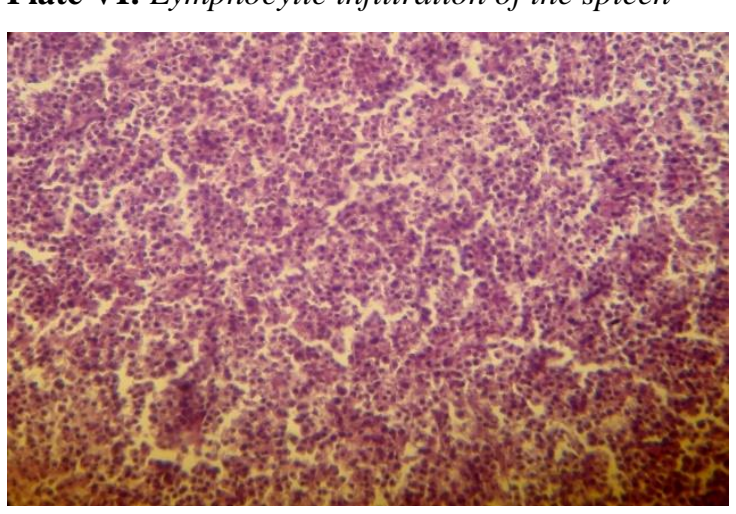

\subsection{Confirmatory Diagnosis}

Marek's Disease

\subsection{Recommendation}

Isolation of sick chickens

Farmers should ensure proper vaccination

Repeat MD vaccination

Strict biosecurity

Keep younger birds separately from older birds

Practice 'all-in and all-out' policy

Careful selection of the source of fresh stock is vital in maintaining a disease free stock.

\section{ACKNOWLEDGEMENT}

The farmer for presenting the case to CDL

Central diagnostic laboratory

Virology laboratory

Parasitology laboratory

\section{REFERENCES:}

[1] Adene, D. F. and Akpavie S.O. (1997). A general overview of Marek's disease ofpoultryin

[5] Fenner FJ, Gibbs EP, Murphy FA, Rott R, Studdert MJ, White DO (1993). Veterinary Virology (2nd ed.). Academic Press, Inc. ISBN 978-0-12-253056-2.

[6] Hill, D. H. and Davis, O. S. (1962). Disease incidence, age and seasonal trends inpoultry flock losses at University College, Ibadan, Nigeria, West Africa. Journalof Biological.Chemistry,5:5-58.

[7] Hirai K, ed. (2001). Current Topics in Microbiology and Immunology: Marek's Disease (Current Topics in Microbiology and Immunology). Springer: Berlin. ISBN 978-3540-67798-7.

[8] Islam AF, Wong CW, Walkden-Brown SW, Colditz IG, Arzey KE, Groves PJ (October 2002). "Immunosuppressive effects of Marek's disease virus (MDV) and herpesvirus of turkeys (HVT) in broiler chickens and the protective effect of HVT vaccination against MDV challenge". Avian Pathology. 31 (5): 449-61. doi:10.1080/0307945021000005824. PMID 12427339 .

[9] Jwander L. D., Abdu P. A., Ibrahim N. D. G. and Nok A. J. (2014).Retrospectivestudies of Marek's disease diagnosed in four States across Nigeria.Journal ofVeterinary Advances, 4(6): 556-563.

[10] Jwander, L. D., Abdu, P. A., Owoade, A. A., Ekong, P. S., Ibrahim, N.D.G. and Nok, A.J.(2012). Molecular detection of Marek's disease virus in avian species fromNorth Central Nigeria.Vom Journal of Veterinary Science, 9: $77-82$.

[11] Nawathe, D.R., Ojeh, C.K. and Onunkwo, O. (1978). Incidence of Marek's disease inNorthern states of Nigeria. Veterinary Record, 102:128. 
[12] OIE Terrestrial Manual (2010), Chapter 2.3.13. Marek's Disease", Retrieved 2012-08-03

[13] Okwor, E. C. and Eze, D., C.(2011). Outbreak and persistence of Marek's diseases inBatches of birds reared in a poultry farm located in Nsukka, South East Nigeria.International Journal of Poultry Science, 10(8): 617-620.

[14] Olabode, H.O.K., Jwander, L.D., Moses, G.D., Ighodalo, E. and Ebaidomeh, S.A. (2009).Prevalence of avian leukosis and Marek's disease in Ilorin, Kwara State,Nigeria.Nigerian Veterinary Journal, 30(3): 64-68.

[15] Read AF, Baigent SJ, Powers C, Kgosana LB, Blackwell L, Smith LP, Kennedy DA, WalkdenBrown SW, Nair VK (July 2015). "Imperfect Vaccination Can Enhance the Transmission of Highly Virulent Pathogens". PLoS Biology. 13 (7): e1002198. doi:10.1371/journal.pbio.1002198. PMC 4516275. PMID 26214839.

[16] Wakawa, A., M., Muhammad, Z. K., Aliyu, H. B. and Mohammed, B. (2012). Aretrospective analysis of Marek's disease diagnosed at Poultry Clinic of AhmaduBello University, Zaria, Nigeria. Journal of Veterinary Advances, 2(8):424-429.

[17] Witter RL, Gimeno IM, Pandiri AR, Fadly AM (July 2010). "Tumor diagnosis manual: the differential diagnosis of lymphoid and myeloid tumors in the chicken". American Association of Avian Pathologists. 1: 1-84.

[18] World Organization for Animal Health (2018). Reference Experts and Laboratories", Retrieved 2018-12-13

Citation: Barde IJ, et al. Marek's Disease in A Flock Of 32 - Week Old Commercial Laying Birds. ARC Journal of Animal and Veterinary Sciences. 2021; 7(1):1-6. DOI: https://doi.org/10.20431/2455-2518.0701001.

Copyright: (C) 2021 Authors. This is an open-access article distributed under the terms of the Creative Commons Attribution License, which permits unrestricted use, distribution, and reproduction in any medium, provided the original author and source are credited. 